\title{
Assessment of knowledge, attitude and practice of generic medicines among the interns and post graduate dental students: comparison with medical practitioners
}

\author{
Sukhpreet Kaur* \\ Department of Pharmacology, Dasmesh Institute of Research and Dental Sciences, Faridkot, Punjab, India
}

Received: 03 July 2020

Revised: 09 August 2020

Accepted: 10 August 2020

*Correspondence:

Dr. Sukhpreet Kaur,

Email: drsukhpreetchd@gmail.com

Copyright: $\odot$ the author(s), publisher and licensee Medip Academy. This is an open-access article distributed under the terms of the Creative Commons Attribution Non-Commercial License, which permits unrestricted non-commercial use, distribution, and reproduction in any medium, provided the original work is properly cited.

\begin{abstract}
Background: India is one of the highest per capita out-of-pocket health expenditures (62\%) country and use of generics can save a lot of money which can be used for other health issues. Lack of knowledge about cost effectiveness of generic medicines among the health-care professionals had led to a low rate of generic medicine prescription. The objective of this study was to explore the knowledge, attitude and practice of dental students towards the generic medicines.

Methods: A cross-sectional study was carried out using questions from pretested and validated questionnaire which are applicable to Indian scenario. A 22 items questionnaire were distributed to the participants to assess their knowledge, attitude and practice of generic medicine. All the Interns and MDS students were included in this study. The collected data was analyzed using microsoft excel.

Results: $63.4 \%$ participants agreed generics can be interchanged with a branded drug. $89.74 \%$ participants were aware that bioequivalence studies are conducted by generic manufacturers for all the marketed generic medicines. Mostly participants (78.04\%) were of opinion that generic medicines do not produce greater side effects than branded drugs. $54.05 \%$ participants reported that they were prescribing generic medicines. $52.38 \%$ participants were aware that generic medicine contains the same active substances as that innovator and used at same dose to treat same disease.

Conclusions: In our study, we found that the prescribers had a considerable knowledge regarding the concept of generic medicines. However, to further increase the rate of generic medicine prescription training programs on generic medicines should be organized.
\end{abstract}

Keywords: Generic medicines, Dental practitioners, Knowledge assessment

\section{INTRODUCTION}

The increasing health-care expenditures remain a serious concern for the health-care system worldwide. In developing countries approximately $80 \%$ healthcare expenditure is paid from patients' pocket. ${ }^{1}$ As patient is bearing the cost of treatment themselves, it is necessary to keep health-care expenditure minimal without compromising the quality of care. One of the major components of health-care expenditure is cost of the medicines. ${ }^{2}$ The price of generic medicines is $10-80 \%$ lower than their branded equivalents. Hence, the usage of generic medicines can improve the access to health-care without conceding the quality. ${ }^{3}$

Generics medicines are alternatives for original (branded) medicines with the equivalent quality, safety and effectiveness. Prescribing generics in clinical practice can 
significantly decrease the health-care expenditure. The government agencies and health-care payers can also be benefit by this. ${ }^{4}$ Given the limited existing resources in India, increasing utilization of generics can be helpful in providing quality health-care to the large population. This will improvise the affordability of the quality health-care facilities to population. ${ }^{5}$

In Indian set up, various initiatives have been taken by various stakeholders to increase adoption of generic prescribing in clinical practice. The Medical Council of India, made an amendment in 2018 in the code of conduct for doctors, recommending that every physician should prescribe drugs with generic names. ${ }^{5}$ The government of India, through the department of pharmaceuticals, started an initiative "Jan Aushadi". The aim of this program is to provide unbranded quality medicines available to poor people in country at a reasonable and affordable price. Until 2018, 3200 Jan Aushadi stores are operating in India but still these are not enough to meet requirements of the Indian population. $^{6}$

Despite all the initiatives, generic prescribing is not very much adopted in Indian scenario. The market share of branded medicines is $90 \%$ of the Indian domestic pharmaceutical market which is approximately Rs. $1,00,000$ crore and more. ${ }^{7}$ Despite of India being one of the major producers and exporter of generic medicines in world, it is reflected that enough generic name equivalents of branded medicines are not sold in Indian market. ${ }^{8}$ There have been various studies showing that perception of physician about generic medicines have been one of the major deterrents in adoption of generic prescribing. 9,10

Also, it has been reported that lack of awareness about regulatory standards used in generic manufacturing is also a barrier is adoption of generic prescribing. ${ }^{11}$ The lack of knowledge about generics emerges as one of the major barriers in generic prescribing. Based on reported literature, this study is designed to assess the awareness of dental practitioners about generic prescribing.

\section{Aim}

To assess the awareness among the interns and post graduate dental students about generic prescribing and compare the knowledge, attitude and practice with the medical practitioners in India.

\section{METHODS}

A cross-sectional study was carried out among interns and post graduate (MDS) dental students in December 2019. The study was conducted at Dasmesh Institute of Research and Dental Sciences, Faridkot, Punjab after taking permission from the Institutional Ethics Committee. The questionnaire consists of pre-validated and self-administered questions applicable to Indian scenario. These questions were taken from published literature pertaining to Indian set up. ${ }^{12-15}$ The questionnaire comprised of 22 items question related to knowledge, attitude and practice (KAP) of generic medicines and about demographics details of participants. The questionnaire contained ten questions assessing knowledge of generic medicine, five questions eliciting participants attitude towards generic medicine, six questions related to practice of generic medicines and one question capturing suggestions to improve generic prescribing in India. The responses were collected in dichotomous response (yes or no). Only one open ended question seeking suggestions to improve generic prescribing in India was there. The pilot testing of questionnaire was done randomly on ten interns of the institute.

The literature search was conducted to find the studies assessing awareness on generic drugs among medical practitioner in an Indian setting.

Data was compiled and analyzed using microsoft excel. The data from dental practitioners and medical practitioners was compared using the Med Calc statistical software. ${ }^{16}$ The responses from two studies were compared using Chi-squared test.

\section{RESULTS}

This study included 42 participants out of which 32 were interns and 10 were MDS students. The average age of participants is 23.14 years. Among participants $76 \%$ were females and $24 \%$ were males.

\section{Knowledge}

The knowledge related questions and frequency of response of the participants is shown in Table 1. It is evident from the table that $61.9 \%$ percent dentists agreed generics intended to interchanged with a branded drug. Only half of the participants were aware that generic medicines were marketed after the expiry of the patent period of the innovator drug and $52.4 \%$ dentists had knowledge that composition, dose and indications of generic medicines were same as the branded counterparts. Among the study participants $31 \%$ were aware that repetition of preclinical and clinical studies wasn't required for manufacturing generic medicines.

An $85.7 \%$ of the participants believed that generic medicines were important tool to reduce the overall health expenditure. An $71.4 \%$ of dentists were aware that drugs with generic names should be prescribed by every physician as stated in the Indian medical council act (professional conduct, etiquette and ethics) regulations, 2002. Only $23.8 \%$ participants told that they were aware regarding the Jan Aushadi scheme. But when they were asked to explain only $9.5 \%$ could explain it correctly and only $14.2 \%$ knew Jan Aushadi stores were located in nearby area. 
Table 1: Knowledge-related questions and frequency (\%) of responses.

\begin{tabular}{|c|c|c|}
\hline Questions & Yes & No \\
\hline $\begin{array}{l}\text { Generic medicines intended to be } \\
\text { interchangeable with a branded } \\
\text { drug }\end{array}$ & 61.9 & 35.7 \\
\hline $\begin{array}{l}\text { Generic medicines only marketed } \\
\text { after expiry of patent period of } \\
\text { innovator drug }\end{array}$ & 50 & 45.2 \\
\hline $\begin{array}{l}\text { Composition, dose and indications of } \\
\text { generic medicines are same as } \\
\text { branded medicine }\end{array}$ & 52.4 & 47.6 \\
\hline $\begin{array}{l}\text { Preclinical and clinical studies are } \\
\text { repeated for manufacture of generic } \\
\text { drugs }\end{array}$ & 64.3 & 31.0 \\
\hline $\begin{array}{l}\text { To reduce overall health } \\
\text { expenditure generic medicines are } \\
\text { important tool }\end{array}$ & 85. & 14.3 \\
\hline $\begin{array}{l}\text { Generic medicines manufacturers } \\
\text { need to conduct bioequivalence } \\
\text { studies }\end{array}$ & 83.3 & 9.5 \\
\hline $\begin{array}{l}\text { Indian medical council act } \\
\text { (Professional conduct, etiquette and } \\
\text { ethics) regulations, } 2002 \text { states that } \\
\text { every physician should, as far as, } \\
\text { possible, prescribe generic medicines }\end{array}$ & 71.4 & 21.4 \\
\hline $\begin{array}{l}\text { Brand name medicines produce } \\
\text { lesser effect than generic medicines }\end{array}$ & 21.4 & 76.4 \\
\hline $\begin{array}{l}\text { Aware about the Jan Aushadi } \\
\text { Yojana launched by government of } \\
\text { India }\end{array}$ & 23.8 & 73.8 \\
\hline
\end{tabular}

\section{Attitude}

It is found that majority of dentists $(76.2 \%)$ were of view that generic medicines do not produce greater side effects than branded drugs as shown in Table 2.

Table 2: Attitude related questions and frequency (\%) of responses.

\begin{tabular}{|lll|}
\hline $\begin{array}{l}\text { Questions } \\
\text { Geseric are not as effective as }\end{array}$ & \multirow{2}{*}{ No } \\
brand-name & 69 \\
\hline $\begin{array}{l}\text { Brand-name drugs are made in } \\
\text { modern manufacturing facilities, } \\
\text { and generics are often made in } \\
\text { substandard facilities }\end{array}$ & 54.8 & 40.5 \\
\hline $\begin{array}{l}\text { Generic drugs cost less because they } \\
\text { are inferior to brand-name drugs }\end{array}$ & 50 & 50 \\
\hline $\begin{array}{l}\text { Quality testing of generics should } \\
\text { be made more vigorous }\end{array}$ & 76.2 & 14.3 \\
\hline $\begin{array}{l}\text { Do you think there should be } \\
\text { training program to increase the } \\
\text { awareness regarding generic drugs }\end{array}$ & 81 & 14.3 \\
\hline
\end{tabular}

Further, $31 \%$ participants believe that the generics are not as effective as brand-name. Almost half of participants
(54.8\%) believed that generic medicines were often made in substandard facilities as compared to brand name drugs. Another $50 \%$ participants did not agree that generic drugs cost less because they are inferior to brand name drugs. Three-quarter $(76.2 \%)$ of the participants were of the view that quality testing of generic medicines should be made more vigorous. Majority participants $(81 \%)$ agreed that there should be training program to increase the awareness regarding generic drugs among doctors and patients.

\section{Practice}

The practice related question and the responses of the participants are summarized in the Table 3. Almost half of the participants $(47.6 \%)$ said that they prescribed generic medicines. Sixty-nine percent of the participants have not read any article on comparison of safety and efficacy of generic versus brand name medicines. A majority $45.2 \%$ of the doctors did not think that switching a patient from a brand name to generic medicines might change the outcome of therapy. Another $69 \%$ of the participants were not comfortable if pharmacist changed branded drugs prescribed by them. Almost half of participants $(54.8 \%)$ supported substitution in all cases where generic is available.

Table 3: Practice related questions and frequency (\%) of responses.

\begin{tabular}{|c|c|c|}
\hline Questions & Yes & No \\
\hline $\begin{array}{l}\text { Pharmacists should be allowed to } \\
\text { substitute the innovator drug with } \\
\text { generic version }\end{array}$ & 69 & 26.2 \\
\hline Do you prescribe generic medicines & 47.6 & 40.5 \\
\hline $\begin{array}{l}\text { Have you anytime read any article } \\
\text { on comparison of safety and efficacy } \\
\text { of generic versus branded medicines }\end{array}$ & 21.4 & 69 \\
\hline $\begin{array}{l}\text { Do you think that switching a patient } \\
\text { from a brand name to generics may } \\
\text { change the outcome of the therapy }\end{array}$ & 50 & 45.2 \\
\hline $\begin{array}{l}\text { Do you support substitution in all } \\
\text { cases where generic is available }\end{array}$ & 54.8 & 40.5 \\
\hline
\end{tabular}

The top two considerations while prescribing a medicine to patients were economic profile of patient $(85.7 \%)$ and efficacy and safety profile of drugs (83.3\%). The availability of drugs in pharmacies is considered by $76.2 \%$ participants and $69 \%$ participants considered price of medicine. These two were next important determinants for choice of drug to be prescribed. Only $45.2 \%$ participants considered pressure from patients to prescribe low cost medicines. The participants suggested that awareness regarding generic prescribing should be increased through various workshops, seminars and continuing education programs. Also, participants suggested that laws should be drafted and enforced regarding prescribing of generic medicines. 
Table 4: Comparison of significantly different responses of dental and medical practitioners.

\begin{tabular}{|c|c|c|c|c|c|}
\hline Questions & $\begin{array}{l}\text { Present } \\
\text { study }\end{array}$ & $\begin{array}{l}\text { Gupta et al } \\
2015\end{array}$ & $\begin{array}{l}\text { Bhattacharjee } \\
\text { et al } 2017\end{array}$ & $\begin{array}{l}\text { Gupta et al } \\
2018\end{array}$ & $\begin{array}{l}\text { Gawali et al } \\
2018\end{array}$ \\
\hline \multicolumn{6}{|l|}{ Knowledge } \\
\hline $\begin{array}{l}\text { Generic medicines only marketed } \\
\text { after expiry of patent period of } \\
\text { innovator drug }\end{array}$ & 50 & $57.5(0.438)$ & $20(0.002)$ & $56.2(0.50)$ & \\
\hline $\begin{array}{l}\text { Composition, dose and indications } \\
\text { of generic medicines are same as } \\
\text { branded medicine }\end{array}$ & 52.4 & $76.7(0.007)$ & $92.5(<0.001)$ & $89.9(<0.001)$ & \\
\hline $\begin{array}{l}\text { Generic medicines manufacturers } \\
\text { need to conduct bioequivalence } \\
\text { studies }\end{array}$ & 83.3 & $79.8(0.325)$ & $95(0.016)$ & $77.7(0.46)$ & \\
\hline $\begin{array}{l}\text { Indian medical council act } \\
\text { (professional conduct, etiquette and } \\
\text { ethics) regulations, } 2002 \text { states that } \\
\text { every physician should, as far as, } \\
\text { possible, prescribe generic } \\
\text { medicines }\end{array}$ & 71.4 & $79.5(0.325)$ & $90(0.003)$ & $80.9(0.22)$ & \\
\hline $\begin{array}{l}\text { Aware about the Jan Aushadi } \\
\text { Yojana launched by government of } \\
\text { India }\end{array}$ & 23.8 & $45.2(0.023)$ & $100(<0.001)$ & $67.4(<0.001)$ & $45.2(0.023)$ \\
\hline \multicolumn{6}{|l|}{ Attitude } \\
\hline $\begin{array}{l}\text { Brand-name drugs are made in } \\
\text { modern manufacturing facilities, } \\
\text { and generics are often made in } \\
\text { substandard facilities }\end{array}$ & 40.5 & $58.9(0.051)$ & $60(0.037)$ & $64(0.008)$ & \\
\hline $\begin{array}{l}\text { Generic drugs cost less because } \\
\text { they are inferior to brand-name } \\
\text { drugs }\end{array}$ & 50 & $31.5(0.050)$ & $12.5(<0.001)$ & $41.1(0.190)$ & \\
\hline $\begin{array}{l}\text { Quality testing of generics should } \\
\text { be made more vigorous }\end{array}$ & 76.2 & & $92.5(0.0048)$ & $31.5(0.050)$ & \\
\hline $\begin{array}{l}\text { Do you think there should be } \\
\text { training program to increase the } \\
\text { awareness regarding generic drugs }\end{array}$ & 81 & $89.0(0.2348)$ & $95(0.005)$ & $89.0(0.234)$ & $55.8(0.005)$ \\
\hline \multicolumn{6}{|l|}{ Practice } \\
\hline $\begin{array}{l}\text { Pharmacists should be allowed to } \\
\text { substitute the innovator drug with } \\
\text { generic version }\end{array}$ & 69 & & $17.5(<0.001)$ & $11.2(<0.001)$ & $59.9(0.2680)$ \\
\hline Do you prescribe generic medicines & 47.6 & $46(0.061)$ & $92.5(<0.001)$ & $86.5(<0.001)$ & \\
\hline $\begin{array}{l}\text { Have you anytime read any article } \\
\text { on comparison of safety and } \\
\text { efficacy of generic versus branded } \\
\text { medicines }\end{array}$ & 21.4 & $38.4(0.061)$ & $27.5(0.435)$ & $65(<0.001)$ & $45.60(0.003)$ \\
\hline $\begin{array}{l}\text { Do you think that switching a } \\
\text { patient from a brand name to } \\
\text { generics may change the outcome } \\
\text { of the therapy }\end{array}$ & 50 & $28.8(0.023)$ & $25(0.002)$ & $19.1(<0.001)$ & \\
\hline $\begin{array}{l}\text { Do you support substitution in all } \\
\text { cases where generic is available }\end{array}$ & 54.8 & $31.5(0.014)$ & & & \\
\hline
\end{tabular}

Data is represented as percentage ( $\mathrm{p}$ value).

\section{Comparison with medical practitioner}

From literature four studies were identified which assess awareness on generic drugs among doctors in Indian set up. All the four studies have been conducted in recent years (2015-2018). Gupta et al conducted a study in 2015 and included 73 doctors working at the tertiary care hospital. ${ }^{13}$ Bhattacharjee et al conducted similar study in 2017 in tertiary teaching hospital among 120 doctors. $^{14}$ Two studies conducted in 2018 included 89 medical practitioners from tertiary care hospital (15) and 217 
prescribers comprising interns, residents and the teaching faculty from tertiary hospital. ${ }^{16}$

It was observed that there were few items in the questionnaire in which there was no significant difference in the response of medical and dental practitioners. The Table 4 shows comparison of responses of dental and medical practitioners which were significantly different.

It was observed that the participants of Bhattacharjee et al study were significantly less aware than other about fact that generics medicines are marketed after expiry of patent period of innovator drug. ${ }^{14}$ On contrary the dental practitioners were less aware as compared to medical practitioners that the composition, dose and indications of generic medicines are same as branded medicines. The knowledge of dental practitioners was almost same except one group regarding need to conduct bioequivalence studies for generic medicines and MCI regulation regarding prescribing generics. The dental practitioners were found to have least knowledge regarding the Jan Aushadi Yojana program launched by government of India.

The attitude of medical practitioner about generics was significantly negative as compared to dental practitioners for both the standards of manufacturing facility of generics as well as quality. Both the groups agreed that there should be training program to increase the awareness regarding generic drugs.

The dental practitioners $(69 \%)$ were more supportive for statement whether pharmacist should be allowed to substitute branded drugs with generic version. In two studies almost $90 \%$ practitioners agreed that they prescribe generic medicines which was nearly double than the dental practitioners $(47.6 \%)$. The medical practitioners have read article on comparison of safety and efficacy of generic versus branded medicines more than dental group.

Also, medical practitioners report that switching from branded to generic medicines leads to changes in outcome of therapy. Further, lesser medical practitioners were supporting the substitution in all cases.

\section{DISCUSSION}

To the knowledge of the author this is first study in India which assess KAP of generic medicines among dental prescribers. In India KAP of generic medicines among medical practitioners have been conducted and published. In dentistry drugs are prescribed for transient treatment or treatment particularly for surgical methods. According to a study, the worldwide market for Dental Drug is expected to grow at a CAGR of roughly $5.8 \%$ over the next five years, will reach 5720 million USD in 2024, from 4320 million USD in $2019 .{ }^{17}$ Similarly, in India also dental prescribing market is growing tremendously at the rate of $8 \%$. Dental prescription market for particular disorders, and the oral care market in prescription products is almost 550 crores INR. ${ }^{18}$

All of this emphasizes that the dental practitioners are one of the major prescribers of drugs and should be updated regarding prescribing practices. It has been reported in various countries including Mexico that dental practitioners often make mistakes in prescription as don't have the best possible pharmacological learning. ${ }^{19}$ This study is an attempt to compare the KAP regarding generic medicines among dental and medical practitioners.

Overall, the perception and understanding regarding generic prescribing remains similar in both dental and medical practitioners except for few points. The knowledge of dental practitioners was comparatively less as compared to medical practitioners in aspects such as knowledge about the composition, dose and indications of generic medicines, bioequivalence studies, MCI regulation for prescribing generics. The knowledge of dental practitioners about the Jan Aushadi stores was also limited. It can due to the set-up differences. The dentist usually works in specialty clinics and are not part of main stream hospitals.

Small sample size and limited to single institutional set up are the main limitations of this study. So, the findings of this study cannot be generalized. The studies using self-administered questionnaire, is largely dependent upon the information given by respondents. In spite of the fact that participants were motivated to fill the questionnaire autonomously, still like influences like recall bias and mutual influences could not be eliminated completely. We recommend such studies to be conducted in other parts of the country to know the knowledge and practices of prescription writing. ${ }^{20}$ We have only studied the doctor's perception and understanding regarding generic medicines. The perception and understanding of other health care professionals as well as patients also have critical role in adoption of generic prescribing.

The successful implementation of any policy or product is dependent on the confidence in efficacy, safety and quality of it. There have been various studies showing that perception of physician about the generic medicines have been one of the major barriers in adoption of generic prescribing. A nationwide survey in Malaysia showed that the physician has negative perception about the generic medicines such as $51.7 \%$ stated that generic medicines are less effective than reference. Further $74.2 \%$ of the physicians assumed that the manufacturing and the quality control standards of branded products are much higher than generic medicines. ${ }^{9}$ Another study conducted in Bosnia and Herzegovina reported similar results $60 \%$ respondents agreed that production of generics is in poorer conditions. ${ }^{10}$

Another systematic review reported that perception of physician is dependent on the maturity of healthcare 
system. The physician in less mature healthcare system report large variations regarding control routines, bioequivalence requirement and manufacturer standards for generics. ${ }^{21}$ In Ireland, study was conducted after the health act 2013 legislated generic substitution. This study highlighted the concerns about the generic substitution in vulnerable patient groups including frail, the elderly, those on multiple medicines, with cognitive impairment and suffering from anxiety. ${ }^{22}$

A study conducted in India, showed that the generic and branded were of comparable quality tested using various tests. On contrary to quality tests, negative perception of medicine quality along with other drivers contribute towards more expensive medicines. Trust in the health system merged as an underlying central theme that explained and drive choice of medicines and providers within the local health system. ${ }^{23}$ Similarly, another study conducted in South Africa showed clear difference between perceptions of quality and actual quality of medicines suggesting deficiencies in initiatives by government to spread awareness about the generic medicines which is thus affecting implementation of the generic prescribing. ${ }^{24}$

Drug advertisements by manufacturers also emerged as one of the factors influencing the prescribing/dispensing practices. A survey conducted in Ethiopia reported 39.9\% physicians agreed/strongly agreed that drug advertisements and promotion by the manufacturers would influence their prescribing practice. ${ }^{25}$

The limited knowledge among both dental and medical practitioners and the negative perceptions of physicians about generics is clearly a major road block for implementation of generic prescribing.

\section{Future perspective}

Currently, undergraduate medical and dental students learn the concept of generic drugs during their secondyear pharmacology teachings. In undergraduate and postgraduate training, there is lack of initiatives emphasizing the importance of generic drugs specifically in reducing patient expenses. The medical education curriculum would have to address this inadequacy to make sure that future practicing physicians and dentist are well conversant and comfortable in prescribing generic drugs. ${ }^{26}$ The compulsory prescribing of generics holds no argument in it until the prescribers are certain about the quality of generic drugs. Only providing guidelines will not enhance quality generic drugs in market, central drugs standard control organization should ensure quality of generics with strict regulatory mandate of these guidelines. ${ }^{26}$

\section{CONCLUSION}

In conclusion, information and education particularly in areas of bioequivalence, regulatory aspects and dispelling myths, fears, doubts or false ideas about generic medicines is very important. This will build up the confidence and habit of generic prescribing into our medical and dental fraternity. We recommend such studies to be conducted in other parts of the country to know the knowledge and practices of prescription writing in dental practitioners. In that way, dental council of India can be strongly recommended to make necessary changes in the curriculum in order to benefit patients and overall public health.

Funding: No funding sources

Conflict of interest: None declared

Ethical approval: The study was approved by the Institutional Ethics Committee

\section{REFERENCES}

1. Jamshed SQ, Hassali MA, Ibrahim MI, Babar ZU. Knowledge attitude and perception of dispensing doctors regarding generic medicines in Karachi, Pakistan: a qualitative study. J Pak Med Assoc. 2011;61:80-3.

2. Bakthavathsalam G. Generic drugs: cost effective alternative to branded drug. Health Administrator. 2006;19:16-19.

3. Jamshed SQ, Ibrahim MIM, Hassali MA, Masood I, Low BY, Shafie AA, et al. Perception and attitude of general practitioners regarding generic medicines in Karachi, Pakistan: a questionnaire-based study. Southern Med Rev. 2012;5(1):22-30.

4. Simoens S, Coster DS. Sustaining Generic Medicines Markets in Europe. J Generic Med. 2006;3(4):257-68.

5. Singhal AK, Solanki MN, Dave DJ. Perceptions and Practice of Use of Generic Medicines by Intern Doctors at A Tertiary Care Teaching Hospital: A Cross Sectional Study. Saudi J Med Pharm Sci. 2019;5(11):972-8.

6. Thawani V, Mani A, Upmanyu N. Why the Jan Aushadhi Scheme Has Lost Its Steam in India? J Pharmacol Pharmacother. 2017;8(3):134-6.

7. Stay Happi Pharmacy. The State of Generic Medicines in India. 2019. Available at: https://stayhappi.in/the-state-of-generic-medicines-inindia/\#: :text=At\%20least\%2090\%25\%20of\%20the, generic $\% 20$ name $\% 20$ equivalents $\% 20$ being $\% 20$ sold. Accessed on 20 June 2020.

8. Scroll in Indian government may ask doctors to prescribe medicines under generic names. Is it practical? Available at: https://scroll.in/pulse/835207/indian-governmentmay-ask-doctors-to-prescribe-medicines-undergeneric-names-is-it-practical. Accessed on 18 June 2020.

9. Kumar R, Hassali MA, Saleem F, Alrasheedy AA, Kaur N, Wong ZY, et al. Knowledge and perceptions of physicians from private medical centers towards generic medicines: a nationwide survey from 
Malaysia. J Pharmaceutical Policy Practice. 2015;8:11.

10. Catic T, Avdagic L, Martinovic I. "Knowledge and attitudes of physicians and pharmacists towards the use of generic medicines in Bosnia and Herzegovina”. Med Glas (Zenica). 2017;14(1).

11. Choudhary NK, Denberg TD, Qaseem A. Improving Adherence to therapy and clinical outcomes while containing costs: opportunities from the greater use of generic medications: best practice advice from the clinical guidelines committee of the American College of Physicians. Ann Intern Med. 2016;164:419.

12. Gupta SK, Nayak RP, Vidyarthi SK. A study on the knowledge, attitude and practice of generic medicines among the doctors in a tertiary care teaching hospital in South India. Natl J Physiol Pharm Pharmacol. 2015;5:39-44.

13. Bhattacharjee P, Das L, Ghosh R, Das UK, Chakraborty M. Knowledge, attitude and practice of generic medicines among doctors in a tertiary care teaching hospital of Tripura, India. Int J Basic Clin Pharmacol. 2017;6:1287-92.

14. Gupta R, Malhotra A, Malhotra P. A study on assessment of awareness in generic drugs among doctors in a tertiary care teaching hospital in north India. Int J Res Med Sci. 2018;6:1362-7.

15. Gawali UP, Gurung A, Deshkar AT, Sabat SK. Study of knowledge, attitude and practice of prescribing generic medicines by interns, residents and faculty in a tertiary care teaching hospital. Natl J Physiol Pharm Pharmacol. 2018; 8(12):1631-4.

16. Med Calc Statistical Software. Available at: https://www.medcalc.org/calc. Accessed on 20 April 2020.

17. Market Watch. Dental Drug Market Share, Size 2020 Outlook 2024 Market Trends, Segmentation, Market Growth and Competitive Landscape, Says Market Reports World. Available at: https:/www.marketwatch.com/press-release/dentaldrug-market-share-size-2020-outlook-2024-markettrends-segmentation-market-growth-and-competitivelandscape-says-market-reports-world-2020-03-31. Accessed on 15 June 2020.

18. ET Health World. We should start manufacturing dental materials, it is a $15000 \mathrm{Cr}$ INR market: Sathyanarayanan. Available at: https://health.economictimes.indiatimes.com/news/in dustry/we-should-start-manufacturing-dentalmaterials-it-is-a-15000-cr-inr-marketsathyanarayanan/64551472\#: : text=In\%20India\%2C $\% 20$ all $\% 20$ dental $\% 20$ materials,ionomers $\% 2 \mathrm{C} \% 20 \mathrm{co}$ mposites $\% 2 \mathrm{C} \% 20$ amalgams\%20etc. Accessed on 12 June 2020.

19. Melendez EMT. An evaluation of the pharmacological knowledge of undergraduate and graduate students at UNAM School of Dentistry. Proc West Pharmacol Soc. 2006;49:173-6.

20. Doshi A, Asawa K, Bhat N, Tak M, Dutta P, Bansal $\mathrm{T}$, et al. Knowledge and Practices of Indian Dental Students Regarding the Prescription of Antibiotics and Analgesics. Clujul Medical. 2017;90(4):431-7.

21. Toverud EL, Hartman K, Hakonsen H. A systematic review of Physicians' and Pharmacists' Perspectives in Generic Drug Use: What are the Global Challenges? Appl Health Econ Health Policy. 2015;13:35-45.

22. O'Leary A, Usher C, Lynch M, Hall M, Hemeryk L, Spillane $\mathrm{S}$, et al. Generic medicines and generic substitution: contrasting perspectives of stakeholders in Ireland. BMC Res Notes. 2015;8:790.

23. Aivalli PK, Elias MA, Pati MK. Perceptions of the quality of generic medicines: implications for trust in public services within the local health system in Tumkur, India. BMJ Glob Health. 2018;2:e00064.

24. Patel A, Gauld R, Norris P, Rades T. Quality of generic medicines in South Africa: perceptions versus reality: a qualitative study. BMC Health Services Res. 2012;12:297.

25. Gebrosillassie BM, Betachew SA, Tefera YG, Abebe TB, Mekuria AB, Haile KT, et al. Evaluating patients', physicians' and pharmacy professionals' perception and concern regarding generic medicines in Gondar town, northwest Ethiopia: A multistakeholder, cross-sectional survey. PloS ONE. 2018;3(11):e0204146.

26. Joshi SS, Shetty YC, Karande S. Generic drugs: The Indian Scenario. J Postgrad Med. 2019;65(2):67-9.

Cite this article as: Kaur S. Assessment of knowledge, attitude and practice of generic medicines among the interns and post graduate dental students: comparison with medical practitioners. Int J Basic Clin Pharmacol 2020;9:1398-404. 